\title{
Structural and optical properties of Ge islands grown in an industrial chemical vapor deposition reactor
}

\author{
R. Loo, ${ }^{\text {a) }}$ P. Meunier-Beillard, D. Vanhaeren, H. Bender, M. Caymax, and W. Vandervorst \\ IMEC, Kapeldreef 75, B-3001 Leuven, Belgium \\ D. Dentel, ${ }^{\text {b) }}$ M. Goryll, and L. Vescan \\ Institute of Thin Films and Ion Technology, Research Centre Jülich, D-52425 Jülich, Germany
}

(Received 26 January 2001; accepted for publication 24 May 2001)

\begin{abstract}
The use of Si based materials for optoelectronic applications is hampered by the indirect nature of the band gap. One possible solution by which to improve the radiative light emission is three-dimensional Stranski-Krastanow growth of $\mathrm{Si}_{1-x} \mathrm{Ge}_{x}$ or pure $\mathrm{Ge}$ on top of $\mathrm{Si}$. In this article we give a detailed overview about the growth kinetics observed for $\mathrm{Ge}$ growth in a standard production oriented chemical vapor deposition system. With increasing deposition time, we observed the usual changeover from monomodal to bimodal island distribution. The island morphology and density can be controlled by varying the growth conditions or by applying a thermal anneal after island growth. Island densities up to $2.3 \times 10^{10} \mathrm{~cm}^{-2}$ have been obtained for depositions at $650^{\circ} \mathrm{C}$. A Si cap layer is needed for photoluminescence measurements as well as for some device structures. However, Si capping at $700^{\circ} \mathrm{C}$ leads to nearly total dissolution of small islands and truncation of bigger dome-shaped islands. This can be prevented by reducing the deposition temperature and by changing the $\mathrm{Si}$ gas source. Photoluminescence measurements demonstrate the high layer quality of $\mathrm{Si}$ capped islands by the clear separation between the no-phonon line and the transversal optical (TO) replica and the high peak intensities. The spectral range of the island luminescence is between $1.35(920 \mathrm{meV})$ and $1.50 \mu \mathrm{m}(828 \mathrm{meV})$ and depends on the growth conditions. At $20 \mathrm{~K}$, we found up to 70 times higher values for the integrated no-phonon and the TO luminescence from the islands, compared to the integrated intensity from the $\mathrm{Si}$ TO peak. Nevertheless, the high photoluminescence intensity can be further enhanced by a thermal treatment in a $\mathrm{H}_{2}$ plasma. Clear island luminescence up to $200 \mathrm{~K}$ has been observed after such thermal treatment, which shows the potential of this material system for optoelectronic device applications. (C) 2001 American Institute of Physics. [DOI: 10.1063/1.1389335]
\end{abstract}

\section{INTRODUCTION}

Si based nanostructures like Ge or SiGe dots embedded in $\mathrm{Si}$ receive a lot of attention which is driven by the reduction of device sizes as well as their possible use in optoelectronic applications. One of the advantages of Ge is its compatibility with conventional Si integrated-circuit technology. Self-organizing island growth (Stranski-Krastanow growth ${ }^{1}$ ) of $\mathrm{SiGe}$ or $\mathrm{Ge}$ on $\mathrm{Si}$ might be used to fabricate quantum size dots with high densities, without the need of lithography to prepare small structures. However, it has to be taken into account that, depending on the growth temperature and $\mathrm{Ge}$ content, lattice mismatch may cause either misfit dislocations or islands. ${ }^{2}$ In general, Stranski-Krastanow growth appears only at a critical Ge content, which strongly depends on the growth conditions (especially the growth temperature and pressure). Different deposition techniques have been used to fabricate and to study the growth mechanism of islands (particularly Ge ones). It was found that after deposition of a wetting layer with a thickness of a few monolayers, smaller

\footnotetext{
${ }^{a)}$ Electronic mail: loo@imec.be

${ }^{b}$ Present address: Laboratoire de Physique et de Spectroscopie Electronique UPRES-A CNRS 7014, Universite de Haute Alsace, 4, rue des Freres Lumiere, F-68093 Mulhouse Cedex, France.
}

pyramidal islands with $\{105\}$ facets (huts) and a square base along the $\langle 100\rangle$ directions appear. ${ }^{3-10}$ During further growth, the huts exceed a critical volume and they transform into multifaceted, octagonal-based domes. ${ }^{3-10}$ If the growth continues, very large islands (diameter of $\sim 590 \mathrm{~nm}$ ) appear and dislocations are created inside the island. ${ }^{8-11}$ The changeover from huts to domes strongly depends on the deposition conditions. Using low pressure chemical vapor deposition (LPCVD), Goryll et al. studied the influence of the growth temperature ${ }^{12}$ and the germane $\left(\mathrm{GeH}_{4}\right)$ partial pressure ${ }^{4}$ on the island morphology, while Kamins et al. used reduced pressure CVD (RPCVD) and atmospheric pressure CVD (APCVD) to study the influence of growth temperature, total pressure, and $\mathrm{GeH}_{4}$ partial pressure on the island morphology. ${ }^{3}$ Both groups observed that, with decreasing deposition rate, the transition from hut to dome appears at an earlier stage. This means that, for approximately the same amount of material deposited, a lower growth rate leads to the development of larger dome-shaped islands with a lower island density. This might be important, because in general the size distribution of domes is narrower.

With respect to optoelectronic applications of $\mathrm{Ge}$ or SiGe islands, the material quality is determined by its optical properties. Measurement of photoluminescence (PL) charac- 
teristics allows one to study the effective band gap and the presence or absence of nonradiative recombination centers. Furthermore, information about structural properties can be obtained, such as the thickness uniformity of the wetting layer in between two adjacent dots, as we will show in this article. Because of the high recombination velocity of excitons (electron-hole pairs) at SiGe and Ge surfaces, ${ }^{13}$ a Si cap layer is needed for PL measurements as well as for some optoelectronic device structures. Several groups studied the optical properties of self-organized Ge dots in $\mathrm{Si}^{2,4,10,11,14-17}$ However, their results were not consistent. Vescan et al. ${ }^{2,10}$ and Goryll et al. ${ }^{4,11}$ studied nominal $\mathrm{Si}_{0.7} \mathrm{Ge}_{0.3}$ and $\mathrm{Ge}$ islands, respectively, grown by LPCVD. In the energy range of 900-1000 (for $\mathrm{Si}_{0.7} \mathrm{Ge}_{0.3}$ islands) and $800-900 \mathrm{meV}$ (for $\mathrm{Ge}$ islands), traditional no-phonon (NP) lines and their transverse optical (TO) phonon replica have been observed, whose origin could clearly be attributed to the islands. According to the observations of Goryll et al. the PL from domes exceeds by far that of huts. ${ }^{4}$ The island luminescence at $4 \mathrm{~K}$ is accompanied by luminescence from the twodimensional $\mathrm{Si}_{0.7} \mathrm{Ge}_{0.3}$ or Ge wetting layer. Similar island luminescence, but without luminescence from the wetting layer, has been observed by Brunhes et al. on Ge islands grown by RPCVD. ${ }^{14}$ In the same energy range, Liu et al. ${ }^{17}$ reported luminescence arising from dots and the wetting layer on samples grown by gas source molecular beam epitaxy (GS-MBE). For the dots, no TO replica was observed. Both Chen et al. ${ }^{16}$ and Peng et al. ${ }^{15}$ claim to have observed high intensity room temperature luminescence from MBE grown islands ( $\mathrm{Si}_{0.6} \mathrm{Ge}_{0.4}$ in Ref. 16 and pure Ge in Ref. 15). The observed PL energy is higher than the Si band gap. In both reports, the observations are explained by an indirectto-direct conversion of the energy band.

So, a lot of effort has been spent in studying the deposition mechanism of islands and it has led to an increased understanding of the growth dependence of the island size, distribution, and uniformity. However, the optical properties of the different types of islands (huts and domes) are still under discussion. Furthermore, the effect of Si overgrowth on the structural and luminescence properties of Ge islands on Si (100) has to be taken into account. Kamins et al. as well as Vostokov et al. reported a dome to pyramid transition during thermal in situ annealing of uncapped Ge dots grown at 650 and $700{ }^{\circ} \mathrm{C}$, respectively. ${ }^{5,6} \mathrm{Si}$ overgrowth of Ge dots in a GS-MBE system leads to dissolution of the Ge island apex and reduced island height, ${ }^{17,18}$ which is reflected in the luminescence properties.

In this article we present an extensive study about the deposition of $\mathrm{Ge}$ on (001)-oriented $\mathrm{Si}$. The epitaxial layers in this work were grown in a standard production oriented CVD system, the ASM Epsilon 2000. We first describe the evolution of island formation observed for different growth temperatures and the influence of a thermal anneal on the structural parameters (the density, size, and shape) of uncapped Ge dots. We will compare the observed results with the observations of other groups. Because regular manual interpretation of atomic force microscopy measurements is quite tedious, time consuming, and subject to appreciable bias, we developed a specific interpretation program which leads to increased accuracy and allows one to collect more data with highly improved statistics on an objective basis. In the second part of this article we describe (temperature dependent) PL measurements on Si-capped samples. We discuss all the different growth conditions for the Ge islands as described in Sec. III A 1-3. By using different growth temperatures and different $\mathrm{Si}$ source gases, we studied the influence of the thermal budget during $\mathrm{Si}$ overgrowth on the optical and structural properties of the Ge dots. Furthermore, we discuss the impact on the Ge dots of applying a given thermal budget, either with or without $\mathrm{Si}$ growth.

\section{EXPERIMENT}

The RPCVD system used in this work is an ASM Epsilon 2000 epi reactor, which has been developed for production applications. It is a horizontal, cold wall, single wafer, load-locked reactor, with a lamp heated graphite susceptor in a quartz tube. Epitaxial layers were deposited on blanket 200 mm (001) Si wafers ( $n$ type, $1-10 \Omega \mathrm{cm}$ ). The deposition conditions include a pressure of 40 Torr with a flow of 33 slm $\mathrm{H}_{2}$ as a carrier gas. Dichlorosilane $\left(\mathrm{SiH}_{2} \mathrm{Cl}_{2}\right)$ and silane $\left(\mathrm{SiH}_{4}\right)$ were used as $\mathrm{Si}$ source gases and germane $\left(\mathrm{GeH}_{4}\right.$, $1 \%$ diluted in $\mathrm{H}_{2}$ ) as the Ge source gas. For all $\mathrm{Ge}$ layers we used the same $\mathrm{GeH}_{4}$ partial pressure of $6.1 \times 10^{-5}$ Torr. Before deposition, the wafers received an IMEC clean ${ }^{19,20}$ followed by an in situ bake at $1050{ }^{\circ} \mathrm{C}$ for $30 \mathrm{~s}$ in $\mathrm{H}_{2}$ in order to remove the native oxide. The layer sequence consists of a $\mathrm{Si}$ buffer layer (grown at $800^{\circ} \mathrm{C}$ ) and a Ge layer (grown at 650 or $700^{\circ} \mathrm{C}$ ). For PL measurements, a Si cap layer was deposited on top of the Ge layer. For growth of the Si cap layer we used different growth temperatures and different $\mathrm{Si}$ source gases in order to study the influence of the thermal budget during $\mathrm{Si}$ overgrowth on the optical and structural properties of the Ge dots. The epi system allows in situ anneals after each separate layer.

The Ge dose was measured by conventional Rutherford backscattering spectrometry (RBS) and is expressed in terms of number of equivalent monolayers of Ge (even when islands are present). PL measurements were used to study the optical material properties. PL was carried out with a Fourier transform spectrometer equipped with a $\mathrm{N}_{2}$ cooled Ge detector. The samples were mounted in a continuous-flow He cryostat and excited by an Ar ion laser with a wavelength of 488 nm. Scanning electron microscopy (SEM), plan-view and cross-sectional transmission electron microscopy (TEM), and atomic force microscopy (AFM) were used to study the structural properties. AFM data were measured on a Digital Instruments Nanoscope III Dimension 3000 system. The use of the Nanoscope software for interpretation of the AFM graphs is time consuming and has the drawback that the island maximum is defined by the human eye. In order to avoid human error and to be able to collect more data in a convenient way, we developed a program within the IGOR PRO software environment to characterize the surface morphology of the epitaxial layers and to extract the size distribution of the island. The program itself defines the island maximum and makes four vertical cross sections in the [110] and [100] directions. On each cross section it determines the 


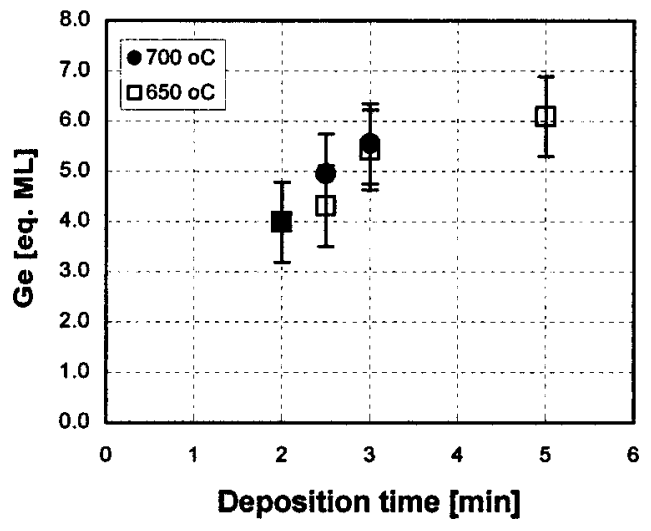

FIG. 1. Amount of Ge deposited as measured by RBS as function of time at 40 Torr and $\mathrm{GeH}_{4}$ partial pressure of $6.1 \times 10^{-5}$ Torr for growth temperatures of 650 and $700{ }^{\circ} \mathrm{C}$. For a deposition time of $2 \mathrm{~min}$ the measured amount of Ge is identical for 650 and $700{ }^{\circ} \mathrm{C}$.

minimum at the two sides of the island profile which gives two island heights, and the island diameter (the distance between the two minimum points). It also allows computation of the angle between island facets and the (001) surface.

\section{EXPERIMENTAL RESULTS}

\section{A. Development of $\mathrm{Ge}$ islands}

\section{Island evolution during Ge deposition}

The evolution of the Ge islands was studied at deposition temperatures of 650 and $700{ }^{\circ} \mathrm{C}$ using deposition times of between 2 and $5 \mathrm{~min}$. For both temperatures, the amount of deposited $\mathrm{Ge}$ increases with the deposition time, which shows the capability to control the deposition process (Fig. $1)$. Within the accuracy of the RBS measurements, it is observed that the total amount of deposited Ge does not depend on the growth temperature. This indicates that, for our growth conditions, limited gas phase mass transfer controls Ge deposition. On the other hand, island growth shows a temperature dependence and this will be discussed below.

For all samples three-dimensional island growth has been observed. For short deposition times (up to $3 \mathrm{~min}$ at $650{ }^{\circ} \mathrm{C}$ and up to $2 \mathrm{~min}$ at $700^{\circ} \mathrm{C}$ ), we observed a monomodal island distribution with only small pyramidal islands with facets (huts) having a square base along the $\langle 100\rangle$ directions. Both the hut diameter and height show a broad distribution (Fig. 2). Similar to in other studies, ${ }^{3,5}$ we observed for both growth temperatures a linear relationship between the diameter and the height of the huts. This indicates uniform island growth, with a stable island shape. The measured facet angle of the huts increases with increasing height and diameter but seems to saturate at $11^{\circ}$ (Fig. 2). This angle corresponds to the $\{105\}$ facets often reported for huts. ${ }^{4-6}$ Some of the smallest huts are not square-based pyramidal but elongated in one $\langle 100\rangle$ direction.

For longer deposition times we observed a bimodal island distribution with square-based faceted huts (mainly $\{105\}$ facets) and multifaceted, octagonal-based domes (Figs. 2 and 3). The shape transition from huts to domes appears at a critical temperature dependent diameter $(130 \mathrm{~nm}$ for $700^{\circ} \mathrm{C}$ and $90 \mathrm{~nm}$ for $650^{\circ} \mathrm{C}$ ) above which the island con-
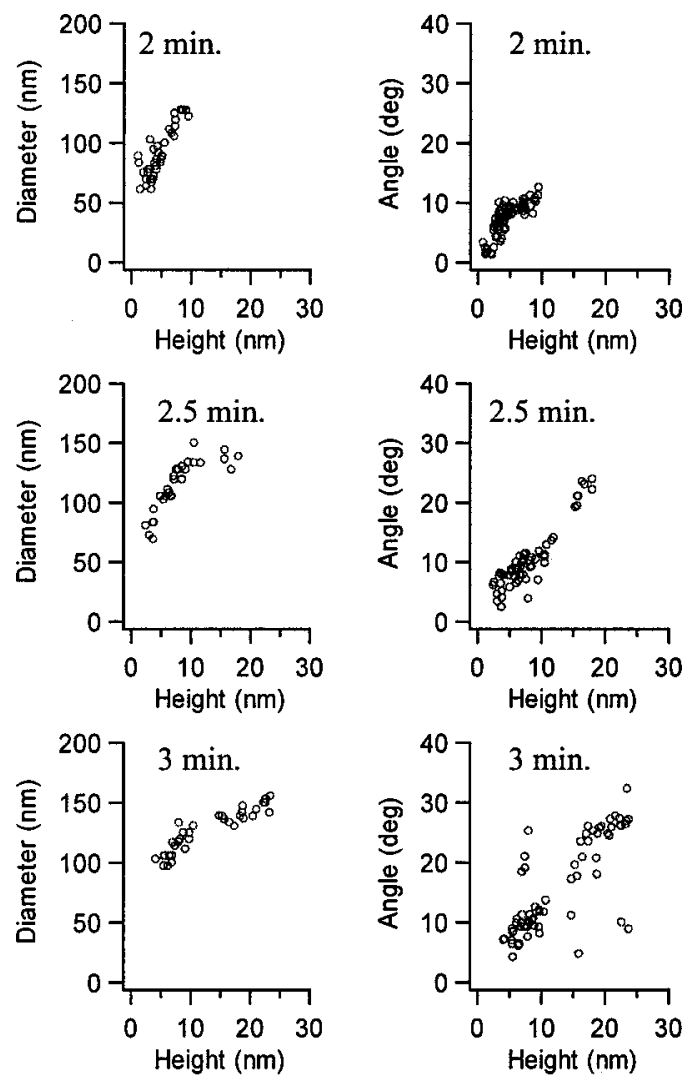

FIG. 2. Ge island evolution determined from AFM images as function of the deposition time. The left side shows the island diameter (measured in the $\langle 100\rangle$ direction) as a function of island height and the right side shows the island angle (measured in the $\langle 100\rangle$ direction) as a function of island height. The islands were deposited at $700{ }^{\circ} \mathrm{C}$.

tinues to grow only in the vertical direction. This shape transition from huts to domes might be caused by the difference in volume dependence of the energy of the surfaces, edges, and interfaces of the huts and domes and possibly by the interaction of strain among different islands. ${ }^{6}$ This means that, above a critical volume, the dome energy becomes less than that of huts. With increasing deposition time, the percentage of domes increases at the expense of huts. Moreover, the shape transition from huts to domes goes with a reduction of the total island density (Fig. 4), which is in contrast to the results observed by other groups. ${ }^{3,5,8}$

The two main differences in the evolution of the Ge islands for the two different growth temperatures (650 and $700{ }^{\circ} \mathrm{C}$ ) are (1) the higher island density at $650{ }^{\circ} \mathrm{C}$ (Fig. 4) and (2) the observation that the shape transition from huts to

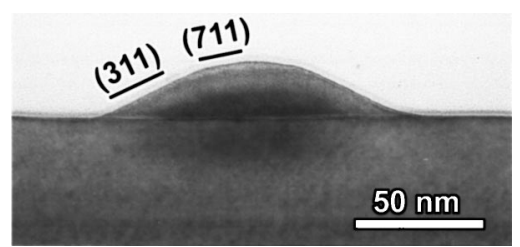

FIG. 3. [01 $\overline{1}]$ cross-sectional TEM micrograph of a dome containing $\{311\}$ and $\{711\}$ facets observed at $700{ }^{\circ} \mathrm{C}$ after 3 min Ge deposition. The height $(22 \mathrm{~nm})$ and diameter $(120 \mathrm{~nm}$ in the $\langle 011\rangle$ direction) are in agreement with the AFM data obtained on the biggest domes. 


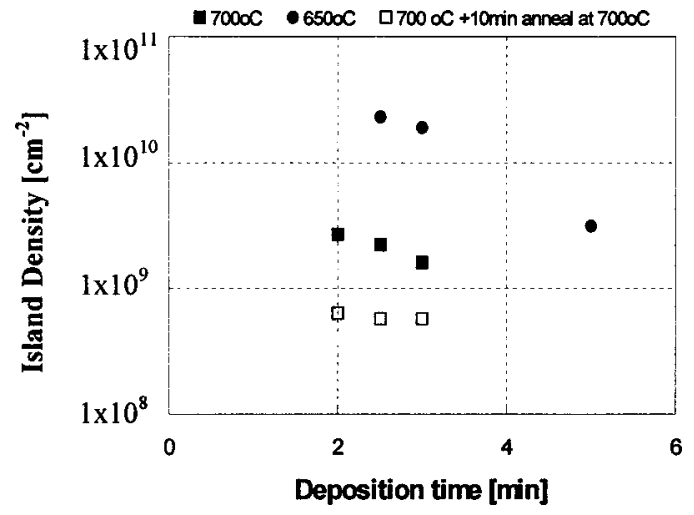

FIG. 4. Island density determined from AFM images as a function of deposition time for different deposition temperatures. The highest island density $\left(2.3 \times 10^{10} \mathrm{~cm}^{-2}\right)$ was observed at $650{ }^{\circ} \mathrm{C}$ for a deposition time of $2.5 \mathrm{~min}$.

domes appears at different deposition times (which means at different deposited Ge doses). These effects can be explained by the lower adatom mobility on the surface with decreasing deposition temperature, which could further be reduced by enhanced hydrogen passivation at lower temperatures. Furthermore, the two-dimensional wetting layer is thicker at lower temperatures (higher critical thickness) which is confirmed by PL measurements on Si capped islands (see below). Therefore, at lower temperatures more Ge has to be deposited before island growth is initiated. Remember, the deposition rate is temperature independent, because the growth is in the mass-transport regime. Therefore, the increase in transition time from hut to dome corresponds to an increase in the amount of Ge deposited.

\section{Island evolution during in situ annealing}

We also studied the evolution of the island distribution during the in situ anneal, which might be of interest for technological reasons. Here in Sec. III A2, we discuss island evolution during the in situ anneal and in Sec. III A3 we will compare it with the effects of Si capping on the island shape.

We deposited $\mathrm{Ge}$ islands at $700{ }^{\circ} \mathrm{C}$ under identical conditions to the samples discussed in Sec. III A1. Immediately after $\mathrm{Ge}$ deposition, the samples received an in situ bake for $10 \mathrm{~min}$ in $\mathrm{H}_{2}$ at the deposition temperature $\left(700^{\circ} \mathrm{C}\right)$ and at 40 Torr. According to RBS, no Ge was lost. The results are summarized in Figs. 4-6, and in Table I. During the in situ anneal, the islands grow further in all directions and the island diameter exceeds the critical value seen during $\mathrm{Ge}$ deposition. Simultaneously, the island density decreases and becomes nearly independent of the Ge deposition time. The changes in island shape and distribution are most dramatic for the shortest deposition time of $2 \mathrm{~min}$. Besides the strong enlargement of the islands, the island distribution is changed from monomodal to bimodal and the island density is reduced by a factor of 4.3 . After $2.5 \mathrm{~min}$ Ge deposition and the in situ anneal, the island distribution remains bimodal but the fraction of domes is enhanced. Compared to deposition times of 2 and $2.5 \mathrm{~min}$, we observed for $3 \mathrm{~min}$ Ge deposition the opposite effect during the in situ anneal: a tendency from a dome to a hut changeover. Furthermore, some islands have a
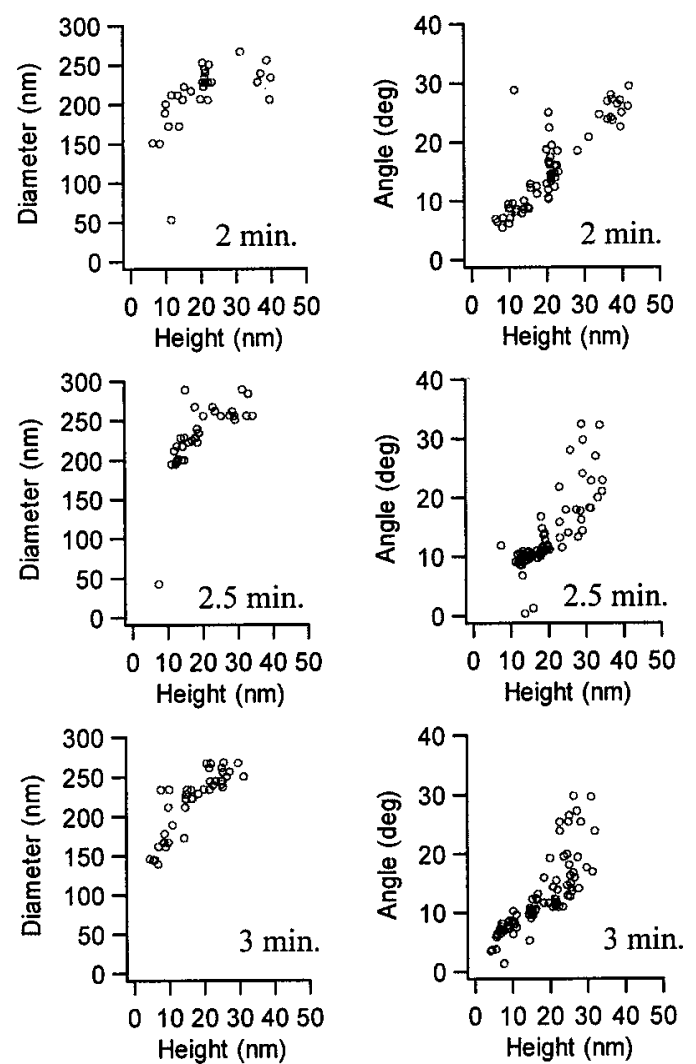

FIG. 5. Relation between island diameter and height (left side) and island angle and height (right side) measured by AFM in the $\langle 100\rangle$ direction. After deposition of the Ge layers at $700{ }^{\circ} \mathrm{C}$, the wafers received an in situ anneal for $10 \mathrm{~min}$ at $700^{\circ} \mathrm{C}$. Different plots are for different Ge deposition times, which are indicated.

complex structure (Fig. 7). One side of these islands has the steep facets of a dome, the other side is broadened and seems to form a less steep facet (possibly $\{105\}$ ).

The shape transition from dome to hut, observed after annealing of Ge islands with a deposition time of 3 min, was also reported by Kamins et al. ${ }^{6}$ on CVD grown samples and by Vostokov et al. ${ }^{5}$ on MBE grown samples. This transformation is opposite to the island evolution during Ge deposition and has been explained by the observed Si diffusion from the substrate into the islands during annealing. ${ }^{5,6}$ The increase of the $\mathrm{Si}$ fraction in the island makes strain de-

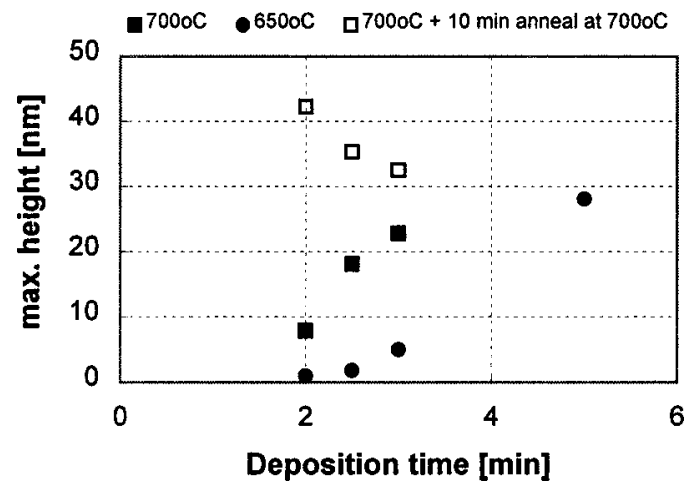

FIG. 6. Maximum island height as a function of deposition time determined from AFM images for Ge islands deposited at $700{ }^{\circ} \mathrm{C}$ (with and without the in situ anneal) and $650{ }^{\circ} \mathrm{C}$ (without the in situ anneal). 
TABLE I. Influence of an in situ anneal $\left(10 \mathrm{~min}\right.$ at $\left.700{ }^{\circ} \mathrm{C}\right)$ on the structural island parameters.

\begin{tabular}{|c|c|c|c|c|c|c|}
\hline \multirow{2}{*}{$\begin{array}{l}\text { Deposition } \\
\text { time }\end{array}$} & \multicolumn{2}{|c|}{$2 \min$} & \multicolumn{2}{|c|}{$2.5 \mathrm{~min}$} & \multicolumn{2}{|c|}{$3 \min$} \\
\hline & As grown & After anneal & As grown & After anneal & As grown & After anneal \\
\hline Max. height (nm) & 7.8 & 42.2 & 18.1 & 35.3 & 22.8 & 32.5 \\
\hline Max. diameter (nm) & 117 & 266 & 145 & 281 & 180 & 273 \\
\hline Density $\left(\mathrm{cm}^{-2}\right)$ & $2.7 \times 10^{9}$ & $6.3 \times 10^{8}$ & $2.2 \times 10^{9}$ & $5.7 \times 10^{8}$ & $1.6 \times 10^{9}$ & $5.7 \times 10^{8}$ \\
\hline Distribution & Monomodal & Bimodal & Bimodal & Bimodal & Bimodal & Bimodal \\
\hline Fraction of huts & 1 & 0.77 & 0.85 & 0.66 & 0.56 & 0.68 \\
\hline Fraction of domes & 0 & 0.23 & 0.15 & 0.34 & 0.44 & 0.32 \\
\hline
\end{tabular}

crease, which leads to a higher critical volume for the huts and explains the transformation back from domes to huts. On the other hand, the shape transition from huts to domes observed after annealing of Ge islands with deposition times of 2 and 2.5 min cannot be explained by Si diffusion. According to the AFM images [Fig. 7(a)], moats surrounding the islands are formed in the Ge layer and the total island density is reduced during the anneal. The formation of moats around the islands was also reported by Chaparro et al. ${ }^{9}$ They are formed via Ge diffusion of the most highly strained material (the wetting layer) from near the island perimeter. Ge diffusion may also explain the spontaneous shrinkage and final disappearance of huts that leads to the formation and enlargement of domes. This mechanism does not change the Ge content within the islands but increases the total island height. Therefore, the observed changeover from huts to domes is in agreement with the results of Sec. III A1.

The detachment of Ge atoms from the metastable huts and the subsequent Ge surface diffusion on top of the twodimensional wetting layer towards stable islands is influenced by interactions between closely spaced islands. ${ }^{21}$ With increasing deposition times we observed a decreasing island density, which will lead to differences among island interac-

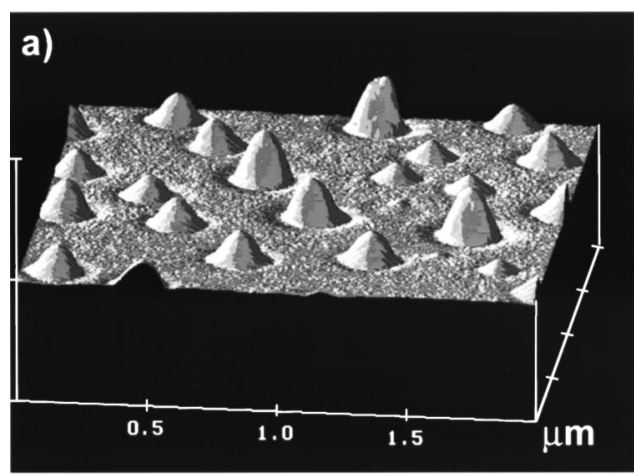

b)

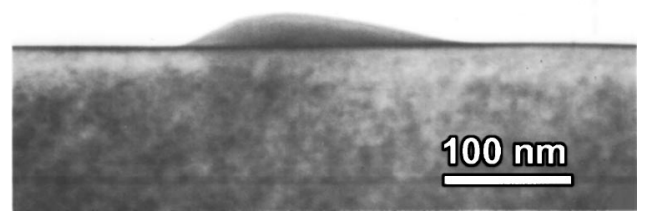

FIG. 7. Ge islands deposited at $700{ }^{\circ} \mathrm{C}$ for $3 \mathrm{~min}$ and annealed at $700{ }^{\circ} \mathrm{C}$ for $10 \mathrm{~min}$. (a) AFM image that shows the asymmetric elliptic structure of some islands. (The vertical scale is $85 \mathrm{~nm}$ ). (b) Cross-sectional TEM micrograph (parallel to the $\langle 110\rangle$ direction) of an asymmetric elliptical island. tion during the in situ anneal as a function of deposition time. A change in island shape is given by a change in island energy. The two diffusion mechanisms, lateral Ge diffusion and $\mathrm{Si}$ diffusion through the islands, have an opposite influence on the island energy. Apparently, the strength of the two mechanisms on the island energy is a function of the island density: the influence on island energy is only dominated by lateral Ge diffusion above a certain island density. This might explain the opposite changeover observed after the anneal (from hut to dome for deposition times of 2 and 2.5 $\mathrm{min}$ and from dome to hut for a deposition time of $3 \mathrm{~min}$ ). Nevertheless, the fact that the highest islands are observed after the in situ anneal of the samples with the shortest deposition time is remarkable. On the other hand, the fraction of domes observed after the anneal is still the lowest for this deposition time (Table I). This observation might also be explained by interactions among closely spaced islands. The detachment of Ge atoms from the metastable huts and their subsequent incorporation on top of the stable islands is more pronounced for higher island densities and leads to a limited number of domes. The highest islands are therefore obtained after annealing of the samples with the highest island density.

\section{Influence of Si overgrowth on island shape}

For devices such as light emitting diodes as well as for PL measurements, Ge islands have to be capped by a $\mathrm{Si}$ layer. The embedding passivates the island surface, leading to an intrinsic potential profile within the quantum dot, and to a well-defined potential barrier between the dot and its environment. However, the overgrowth of the Ge islands with a $\mathrm{Si}$ cap layer has a strong influence on the island morphology (Fig. 8) which could change the electronic and optical properties. A monomodal island distribution with only huts has been observed after 2 min Ge deposition at $700^{\circ} \mathrm{C}$. After capping of these islands by a $\sim 60 \mathrm{~nm}$ thick Si layer at $700{ }^{\circ} \mathrm{C}$ (deposition time of $35 \mathrm{~min}$ ) we do not observe any islands in the cross-sectional TEM (XTEM) micrographs [Fig. 8(a)]. The Ge layer is almost uniform in thickness, only weak undulations are visible. Also after $3 \mathrm{~min}$ of Ge deposition, the domes appear to become lower during the capping step according to the XTEM micrograph [Fig. 8(b)]. It is not guaranteed that during XTEM sample preparation one cuts in all cases through the island apex. In order to improve measurement accuracy, we measured a large number of islands. Still, the largest islands we observe have a height of $10 \mathrm{~nm}$ (23 nm without Si capping) and a length along the $\langle 110\rangle$ direction of $150 \mathrm{~nm}$. Furthermore, the steep $\{113\}$ facets are 


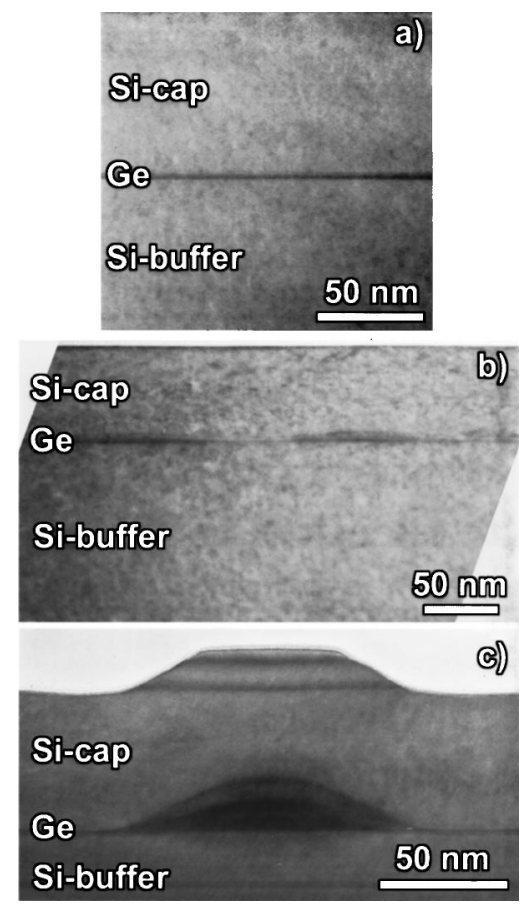

FIG. 8. Cross-sectional TEM micrographs (in the $\langle 110\rangle$ direction) of Ge islands capped by a $60 \mathrm{~nm}$ thick Si layer. The Ge layer was grown at $700{ }^{\circ} \mathrm{C}$ for all samples. (a) Ge deposition time $2 \mathrm{~min}$ and $\mathrm{Si}$ layer grown at $700{ }^{\circ} \mathrm{C}$ for $35 \mathrm{~min}$. (b) Ge deposition time $3 \mathrm{~min}$ and $\mathrm{Si}$ layer grown at $700{ }^{\circ} \mathrm{C}$ for $35 \mathrm{~min}$. (c) Ge deposition time $3 \mathrm{~min}$ and $\mathrm{Si}$ layer grown at $650^{\circ} \mathrm{C}$ for $7 \mathrm{~min} 54 \mathrm{~s}$.

not present anymore. According to plan-view TEM micrographs, the islands are square with some rounding at the edges which indicates a hut shape (Fig. 9). The island diameter is quite uniform, around 100-110 nm. We observed a similar morphology change on Si capped islands with an in situ anneal immediately after deposition of the islands (Fig. 10). The islands grow during the in situ anneal, leading to enhancement of both the height and diameter and the moats surrounding the islands. The moat is still seen in the planview TEM micrograph of the Si capped sample [Fig. 10(b)]. The island growth during the in situ anneal avoids the disappearance of all the islands for a Ge deposition time of $2 \mathrm{~min}$ [Fig. 10(a)].

The dissolution of the island apex, the reduced island height, and the vanishing of small islands has also been observed by other groups. ${ }^{17,18}$ Sutter et al. presented a physical

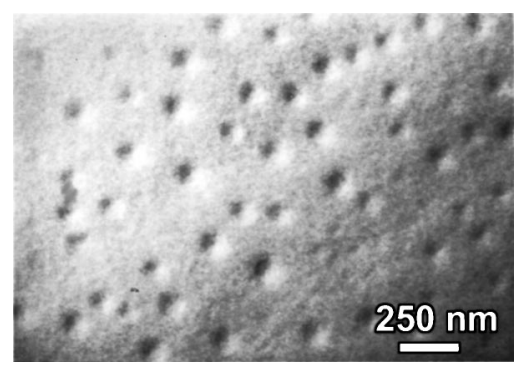

FIG. 9. Plan-view TEM micrographs of Si capped islands corresponding to that in Fig. 8(b), i.e., Ge deposition time 3 min and Si deposition time 35 min, both at $700{ }^{\circ} \mathrm{C}$. The island density $\left(1.5 \times 10^{9} \mathrm{~cm}^{-2}\right)$ is similar to that of the uncapped sample $\left(1.6 \times 10^{9} \mathrm{~cm}^{-2}\right.$ estimated from AFM).

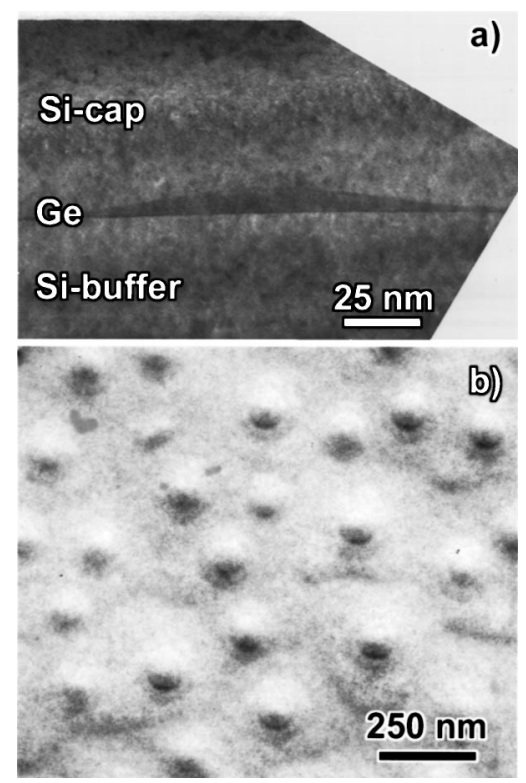

FIG. 10. TEM micrographs of Si capped islands. The sample received an in situ anneal at $700{ }^{\circ} \mathrm{C}$ for $10 \mathrm{~min}$ in between deposition of the Ge layer and the Si cap layer $\left(60 \mathrm{~nm}\right.$, grown at $700{ }^{\circ} \mathrm{C}$ for $35 \mathrm{~min}$ ). (a) Cross-sectional TEM micrograph (in the $\langle 110\rangle$ direction), Ge deposition time 2 min and (b) plan-view TEM micrograph, Ge deposition time $3 \mathrm{~min}$.

interpretation for the dissolution of the island apex, which is driven by the $\mathrm{Si}$ deposition. ${ }^{18,22}$ According to this model, $\mathrm{Si}$ growth is overcompensated for by lateral evaporation of the terrace by atom detachment and by incorporation in the lower part of the island. This imbalance should lead to truncation of the island apex. However, we do not observe the predicted increase in the island diameter nor a $\{001\}$ facet on top of the island.

Because of this kinetical aspect, it is expected that the morphology changes are a function of the deposition rate and deposition temperature during Si capping. We decreased the $\mathrm{Si}$ cap deposition temperature to $650{ }^{\circ} \mathrm{C}$, and increased the growth rate by switching from $20 \mathrm{sccm} \mathrm{SiH}_{2} \mathrm{Cl}_{2}$ to $200 \mathrm{sccm}$ $\mathrm{SiH}_{4}$. Figure 8(c) shows a cross-sectional micrograph of the biggest $\mathrm{Ge}$ island covered by $\mathrm{Si}$. The dome shape is largely retained, with clear $\{113\}$ facets, and a height of $22 \mathrm{~nm}$. The Si cap shows much better step coverage and conformity when it covers the Ge islands, resulting in mesa-like features with flat surfaces. We speculate that this can be explained by lower surface diffusion due to the lower temperature and the higher growth rate. Also, the presence/absence of $\mathrm{Cl}$ in the two $\mathrm{Si}$ precursor gases $\left(\mathrm{SiH}_{2} \mathrm{Cl}_{2}\right.$ versus $\left.\mathrm{SiH}_{4}\right)$ might play a role because of enhanced etching, but this has not been studied in detail. The preservation of island shape happens also for $\mathrm{Ge}$ dots deposited at $650^{\circ} \mathrm{C}$ and capped at $650{ }^{\circ} \mathrm{C}$. The island shape and dimensions are similar to those of the uncapped samples; this means only huts for Ge deposition times of $3 \mathrm{~min}$ or less, and both domes and huts for $5 \mathrm{~min} \mathrm{Ge}$ deposition.

\section{B. Optical properties}

\section{Ge deposited at $700^{\circ} \mathrm{C}$}

The influence of the growth conditions on the island morphology during Si capping is directly reflected in the PL 


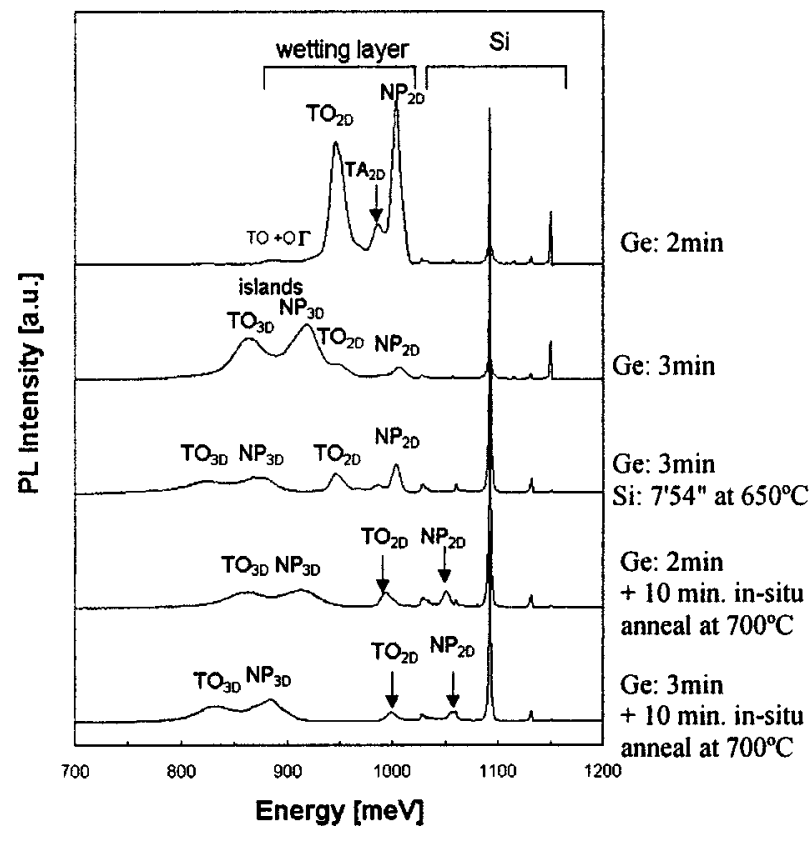

FIG. 11. $4 \mathrm{~K}$ photoluminescence spectra of $\mathrm{Si}$ capped islands measured at a laser excitation power of $50 \mathrm{~mW} / \mathrm{mm}^{2}$. The deposition times of the Ge layer (grown at $700{ }^{\circ} \mathrm{C}$ ) are indicated. The Si cap layer was grown at $700{ }^{\circ} \mathrm{C}$ for $35 \mathrm{~min}$, except for one sample, where the Si cap was deposited at $650^{\circ} \mathrm{C}$ for $7 \min 54 \mathrm{~s}$.

measurements (Fig. 11). The nearly total disappearance of islands, observed after Ge deposition for 2 min and Si capping at $700^{\circ} \mathrm{C}$, leads to the absence of luminescence arising from islands (Fig. 11). In fact, the PL spectrum measured at $4 \mathrm{~K}$ is similar to high quality two-dimensional $\mathrm{Si} / \mathrm{Si}_{1-x} \mathrm{Ge}_{x} / \mathrm{Si}$ heterostructures. ${ }^{13,23,24}$ High intensity, wellresolved NP transitions and their phonon replicas [transverse acoustic (TA), TO, and two-phonon replica $\mathrm{TO}+\mathrm{O}_{\Gamma}$ with $\mathrm{O}_{\Gamma}$ the optical zone center replica] arising from the twodimensional (nominal) Ge layer were observed. The nophonon energy $(1003 \mathrm{meV})$ is much higher than the Ge band gap $(750 \mathrm{meV})$ which is due to the high confinement energy in the very thin $(\sim 2 \mathrm{~nm})$ Ge layer, and possible $\mathrm{Si} / \mathrm{Ge}$ intermixing. The TO peak lies $\sim 58 \mathrm{meV}$ below the NP peak. This represents $\mathrm{Si}-\mathrm{Si}$ vibrations, present because the exciton radius is bigger than the Ge layer. ${ }^{10}$

The possible use of optoelectronic devices is only of interest at room temperature, and above $\sim 125 \mathrm{~K}$ no PL signal is observed from two-dimensional (2D) $\mathrm{Si} / \mathrm{SiGe}$ layers. At higher temperatures, the thermal energy of the holes is high enough to overcome the energy barrier at the heterointerface and the excitons are no longer trapped in the quantum well.

At $4 \mathrm{~K}$ we observe clear island luminescence on $\mathrm{Si}$ capped samples in which the islands, grown at $700^{\circ} \mathrm{C}$, are preserved (Fig. 11). The luminescence at $918 \mathrm{meV}$ (for the $\mathrm{Si}$ cap grown at $700^{\circ} \mathrm{C}$ ) and at $875 \mathrm{meV}$ (for the $\mathrm{Si}$ cap grown at $650{ }^{\circ} \mathrm{C}$ ) is attributed to the NP line emitted from the islands with their TO replicas at 862 and $822 \mathrm{meV}$, respectively. Variation in island thickness, shape, and Ge content within the islands explains the widening of the peaks compared to samples with only $2 \mathrm{D}$ luminescence. But at $4 \mathrm{~K}$, the integrated intensity from the island-based luminescence is

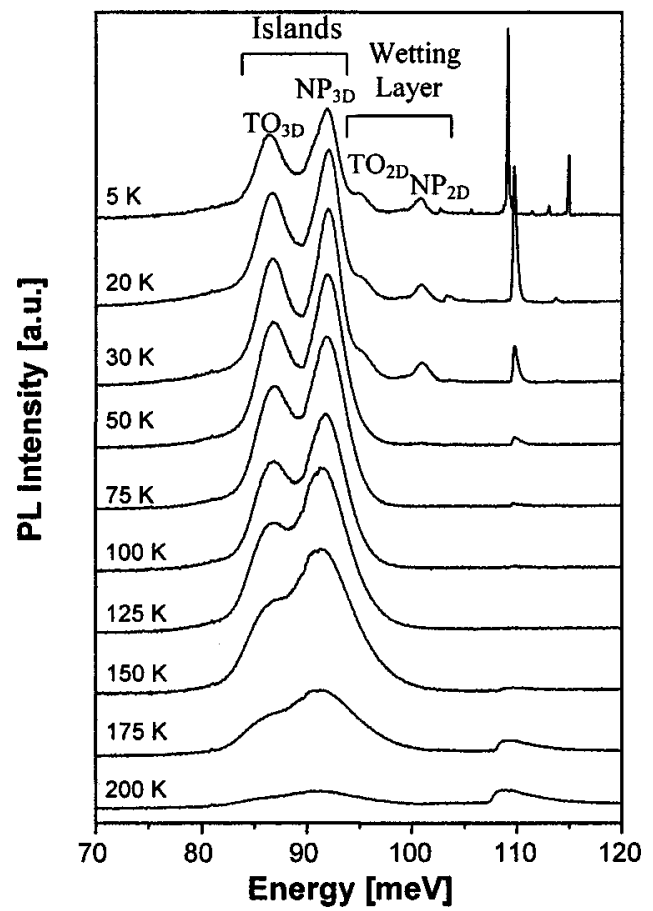

FIG. 12. Photoluminescence spectra measured between 4 and $200 \mathrm{~K}$ at a constant laser excitation power of $50 \mathrm{~mW} / \mathrm{mm}^{2}$. [Figure 8(b) shows the cross-sectional TEM micrograph of the sample.] Ge deposition time $3 \mathrm{~min}$, and Si cap deposition time $35 \mathrm{~min}$, both deposited at $700^{\circ} \mathrm{C}$. After deposition, the sample received a $\mathrm{H}_{2}$ plasma bake $\left(30 \mathrm{~min}\right.$ at $\left.400{ }^{\circ} \mathrm{C}\right)$.

very similar to the 2D-based PL from island-free samples. The island luminescence arises at lower energy compared to the luminescence from the 2D layer. This is because the confinement energy within the islands is less, leading to deeper energy levels in the islands. The fact that we do observe luminescence from the wetting layer at $4 \mathrm{~K}$, in which the photogenerated holes do not find their lowest energy level, is explained by the thickness gradient in the wetting layer. Photogenerated holes captured by the Ge layer follow the potential gradient, defined by the thickness of the wetting layer. ${ }^{25}$ The Ge diffusion from the wetting layer into the islands during $\mathrm{Ge}$ deposition leads to thinning of the wetting layer close to the islands. This results in a lateral potential barrier, which prevents a certain number of the photogenerated holes to reach islands. The thinning of the wetting layer is stronger for samples that received an in situ anneal after the Ge deposition (see Secs. III A2 and III A3). In this case, the Ge diffusion occurs over the entire wetting layer, which leads to an overlap of the Ge depleted regimes from different islands. Therefore, the light emitting part of the wetting layer is also thinned which explains the observed blueshift of the 2D luminescence. At slightly higher temperatures, the thermal energy of the holes is enough to overcome the (lateral) energy barrier and they are able to reach the energetically favored islands. As a result the PL intensity of the wetting layer is reduced (and disappears completely above $50 \mathrm{~K}$ ), and the PL intensity of the islands is slightly enhanced (Fig. 12). The reduction of the $2 \mathrm{D}$ luminescence appears at lower temperatures if an in situ anneal has been applied after the Ge deposition. This indicates a lower lateral energy barrier between the islands and the wetting layer. At $20 \mathrm{~K}$, the integrated 
no-phonon and the TO luminescence from the islands is up to a factor of 70 higher than the integrated intensity from the Si TO peak.

The energy barrier between the island and the $\mathrm{Si}$ is much higher compared to two-dimensional heterostructures. Therefore, the integrated island PL intensity does not decrease until $125 \mathrm{~K}$ and the island luminescence is retained to at least 200 K (Fig. 12). The Si PL intensity decreases by increasing the temperature from 5 to $125 \mathrm{~K}$. Further enhancement of the measurement temperature leads to enhancement of the Si PL intensity (Fig. 12). This effect is not yet fully understood, but might be due to surface band bending initiated by the high pump power. ${ }^{26}$

As we discussed in Sec. III A3, Si capping influences the shape and thickness of the underlying islands albeit to a lower extent if the $\mathrm{Si}$ capping is done at a higher growth rate and a lower temperature. This is reflected in the PL spectra as a redshift of the island luminescence, which can be explained by the reduction of the confinement energy as a function of the island size and as a function of (reduced) $\mathrm{Si} / \mathrm{Ge}$ intermixing (Fig. 11). The peak positions of the island luminescence are $875 \mathrm{meV}(\mathrm{NP})$ and $822 \mathrm{meV}$ (TO), which correspond to wavelengths of 1.5 and $1.4 \mu \mathrm{m}$, respectively. So, the island luminescence appears in the desired spectral range for optoelectronic applications. The reduction of the thermal budget leads to a more uniform thickness of the light emitting part of the wetting layer. This explains the narrower peaks for the 2D luminescence.

We expect that an in situ anneal after Ge deposition will influence the peak positions of the island luminescence. However, the different mechanisms that appear during the anneal, like vertical Si diffusion, lateral Ge diffusion to the islands, and island growth, will have different impacts on the energetical position of the NP and TO lines. The total influence appears to be quite small (Fig. 11).

\section{Defect passivation after a treatment in $\mathrm{H}_{2}$ plasma}

For Ge islands grown and capped at $650{ }^{\circ} \mathrm{C}$, we observe in addition to the Si luminescence only a weak broad band between 700 and $900 \mathrm{meV}$, which is probably defect related. Apparently, nonradiative recombination centers, like vacancy related complexes, are built into the layers. It is known that these defects can be passivated by a $\mathrm{H}_{2}$ plasma treatment at, e.g., $400{ }^{\circ} \mathrm{C}^{24,27,28}$ After this treatment, SiGe luminescence is recovered (Fig. 13). The luminescence observed between $750 \mathrm{meV}$ and $900 \mathrm{meV}$ is an overlap of NP and TO and is attributed to islands. The island luminescence has been shifted toward lower energies in comparison to samples with a $\mathrm{Ge}$ deposition temperature of $700^{\circ} \mathrm{C}$. Due to lower $\mathrm{Si} / \mathrm{Ge}$ intermixing, the $\mathrm{Ge}$ content in the islands might be higher. Contradictory to the $700{ }^{\circ} \mathrm{C}$ case, NP and TO peaks overlap each other, which might be explained by a bigger spread in confinement energy due to thickness variations. The relative variation in energy quantization increases with decreasing layer thickness. For a deposition temperature of $650{ }^{\circ} \mathrm{C}$, the island height is much lower than for a deposition temperature of $700{ }^{\circ} \mathrm{C}$. Furthermore, from the results discussed in Sec. III A 3, we expect that the spread in island dimensions is

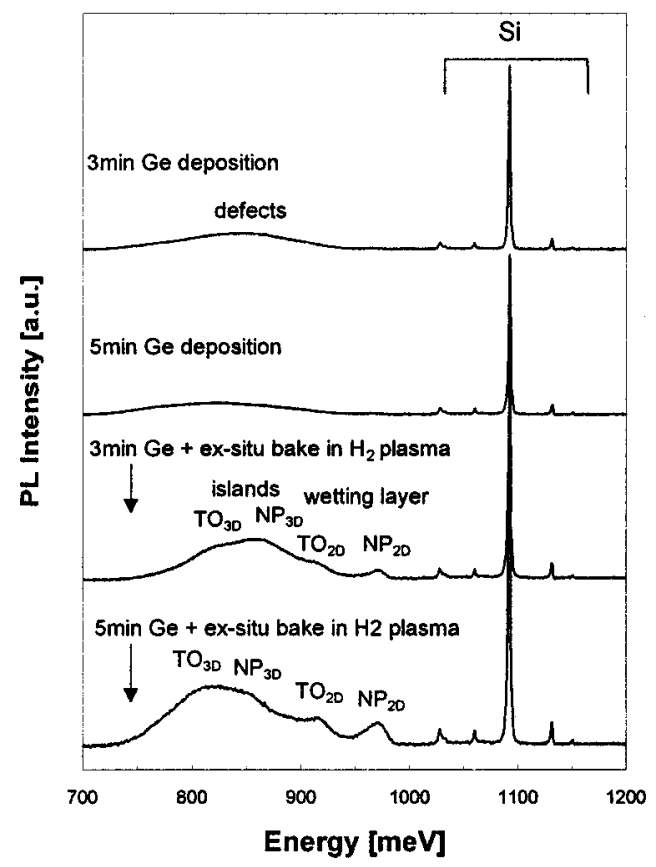

FIG. 13. $4 \mathrm{~K}$ photoluminescence spectra measured at a laser excitation power of $50 \mathrm{~mW} / \mathrm{mm}^{2}$ on $\mathrm{Si}$ capped islands for a growth temperature of $650{ }^{\circ} \mathrm{C}$ for both the Ge layer and the Si cap layer. The PL spectra were taken on as-grown samples and after a bake in $\mathrm{H}_{2}$ plasma at $400{ }^{\circ} \mathrm{C}$. The bake in $\mathrm{H}_{2}$ plasma passivates defects and enhances island luminescence.

retained during $\mathrm{Si}$ overgrowth at $650^{\circ} \mathrm{C}$. Plan-view TEM confirms this at least for the lateral dimensions.

The luminescence around 972 and $916 \mathrm{meV}$ is attributed to the NP line and the TO replica from the $2 \mathrm{D}$ wetting layer. The peak energies are lower compared to the sample with the same deposition temperature for the Si cap layer $\left(650^{\circ} \mathrm{C}\right)$ but with a higher deposition temperature for the $\mathrm{Ge}$ layer $\left(700{ }^{\circ} \mathrm{C}\right)$. This is expected, because the lower growth temperature of the Ge layer leads to higher critical thickness of the 2D layer before island growth appears. Furthermore, reduction of the Ge deposition temperature leads to reduced $\mathrm{Si} / \mathrm{Ge}$ intermixing between the $\mathrm{Si}$ buffer layer and the $\mathrm{Ge}$ layer.

Well-resolved island luminescence, with intensities comparable to the best reported values, has been observed on $\mathrm{Si}$ capped islands grown at $700{ }^{\circ} \mathrm{C}$ (see Sec. III B1). Nevertheless, a treatment in $\mathrm{H}_{2}$ plasma leads to further enhancement of the island luminescence; see Fig. 14. Both the absolute PL intensity as well as the intensity relative to the wetting layer and the Si layer are enhanced. This indicates the presence of defects or dangling bonds in the as-grown sample, in which XTEM could not detect any extended defects. The influence of a $\mathrm{H}_{2}$ plasma bake on the PL intensity shows the possibility for further improvement of the optical layer properties. High quality $2 \mathrm{D} \mathrm{Si} / \mathrm{SiGe}$ quantum wells did not show improvement in PL after a $\mathrm{H}_{2}$ plasma bake. ${ }^{24}$

\section{CONCLUSIONS}

In this work, we discussed the growth kinetics observed for $\mathrm{Ge}$ island growth in a standard production oriented chemical vapor deposition system. Such three-dimensional 


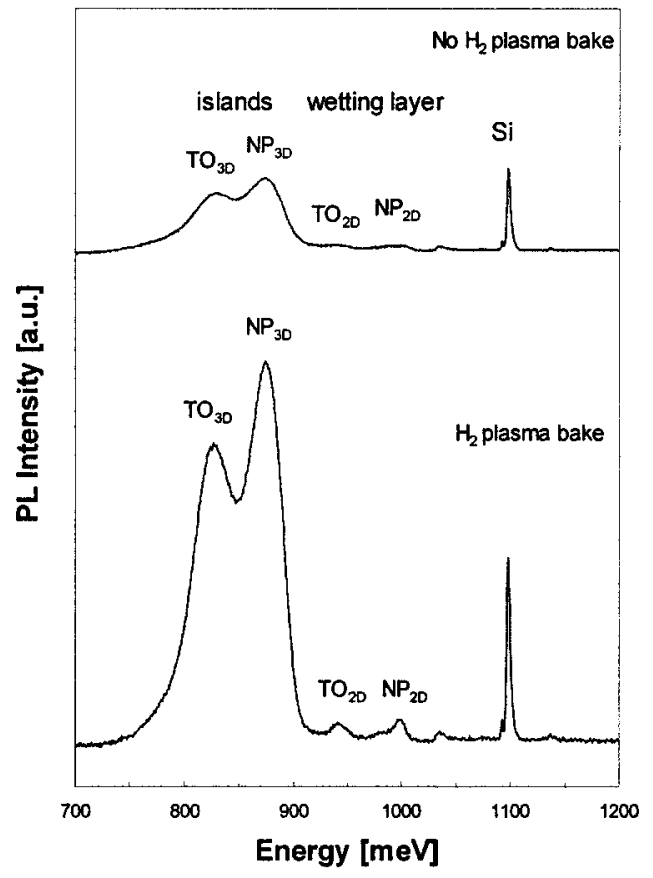

FIG. 14. Influence of a treatment in $\mathrm{H}_{2}$ plasma $\left(30\right.$ min at $\left.400{ }^{\circ} \mathrm{C}\right)$ on the 20 $\mathrm{K}$ photoluminescence (measured at a laser excitation power of 50 $\mathrm{mW} / \mathrm{mm}^{2}$ ). The growth temperature was $700{ }^{\circ} \mathrm{C}$ for the Ge layer and $650{ }^{\circ} \mathrm{C}$ for the Si cap layer.

Ge islands, imbedded in a matrix with a higher energy band gap, are candidates for new electronic and optoelectronic devices. For device applications control of the island size, shape, and uniformity is required. Therefore, the objective of this work was to obtain improved understanding of the growth mechanism during island growth, in situ annealing, and $\mathrm{Si}$ overgrowth of the islands.

With increasing deposition time, a changeover from monomodal to bimodal island distribution appears, which is in agreement with previous studies. The changeover appears for a critical island diameter, which decreases with decreasing temperature. Applying a thermal budget after island growth initiates lateral $\mathrm{Ge}$ surface and $\mathrm{Si}$ diffusion from the substrate through the islands. This leads to enhancement of the critical diameter and the island height, but does so at the expense island density. Furthermore, depending on the island distribution after Ge deposition, a transition from hut to dome shape or visa versa is observed during the in situ anneal.

Ge islands can be successfully implemented in Si based optoelectronic devices, like light emitting diodes (LEDs) ${ }^{29}$ and Infrared (IR) detectors, and in solar cell applications. ${ }^{30}$ LEDs require light emission in the spectral range of 1.3-1.55 $\mu \mathrm{m}$ and up to room temperature. ${ }^{29}$ The implementation of $\mathrm{Ge}$ islands in solar cells should give increased light adsorption in the IR part. ${ }^{30}$ We used PL measurements to study the optical layer properties and to obtain information about structural layer properties. A Si cap layer is needed for these PL measurements as well as for the device structures mentioned above. However, nearly total dissolution of small islands and truncation of bigger dome-shaped islands appear during growth of the cap layer at $700{ }^{\circ} \mathrm{C}$. This was prevented by reducing the deposition temperature and by using $\mathrm{SiH}_{4}$ instead of $\mathrm{SiH}_{2} \mathrm{Cl}_{2}$ as the $\mathrm{Si}$ source gas. PL measurements demonstrate the high layer quality of Si capped islands by the clear separation between the NP line and the TO replica and the high integrated intensities, which was up to 70 times higher compared to the integrated Si TO intensity at $20 \mathrm{~K}$. Island luminescence appears between $1.35(920 \mathrm{meV})$ and $1.50 \mu \mathrm{m}(828 \mathrm{meV})$ which is within the spectral range desired for optoelectronic applications. The high photoluminescence intensity could be further enhanced by a thermal treatment in a $\mathrm{H}_{2}$ plasma. Clear island luminescence up to $200 \mathrm{~K}$ has been observed after such thermal treatments, which shows the potential of this material system for use in optoelectronic device applications. Based on the results obtained, epitaxial layers for LED devices are grown, and device fabrication is currently ongoing.

\section{ACKNOWLEDGMENTS}

The authors wish to thank Bert Brijs and Philippe Roussel for analytical measurements (RBS and TEM, respectively) and Patricia Van Marcke for technical assistance. The authors are indebted to the European Commission (CEC) for financial support in the TMR Network AApples No. FMRXCT96-0029. Three of the authors (R.L., P.M.B., and D.D.) are indebted to the CEC for granting them fellowships in AApples.

${ }^{1}$ I. N. Stranski and L. Krastanow, Sitzungsber. Akad. Wiss. Wien, Math.Naturwiss. Kl., Abt. 2B 146, 797 (1937).

${ }^{2}$ L. Vescan, W. Jäger, C. Dieker, K. Schmidt, A. Hartmann, and H. Lüth, Mater. Res. Soc. Symp. Proc. 263, 23 (1992).

${ }^{3}$ T. I. Kamins, E. C. Carr, R. S. Williams, and S. J. Rosner, J. Appl. Phys. 81, 211 (1997).

${ }^{4}$ M. Goryll, L. Vescan, and H. Lüth, Mater. Sci. Eng., B 69-70, 251 (2000).

${ }^{5}$ N. V. Vostokov, I. V. Dolgov, Yu. N. Drozdov, Z. F. Krasil'nik, D. N. Lobanov, L. D. Moldavskaya, A. V. Novikov, V. V. Postnikov, and D. O. Filatov, J. Cryst. Growth 209, 302 (2000).

${ }^{6}$ T. I. Kamins, G. Medeiros-Ribeiro, D. A. A. Ohlberg, and R. S. Williams, Appl. Phys. A: Mater. Sci. Process. A67, 727 (1998).

${ }^{7}$ D. E. Jesson, in Properties of Silicon, Germanium and SiGe:Carbon, EMIS Datareviews Ser. No. 24, edited by E. Kasper and K. Lyutovich (INSPEC, London, 2000), Chap. 1.1, pp. 3-8.

${ }^{8} \mathrm{~K}$. Tillmann, H. Trinkaus, and W. Jäger in Ref. 7, Chap. 2.4, pp. 63-74.

${ }^{9}$ S. A. Chaparro, Y. Zhang, J. Drucker, D. Chandrasekhar, and D. J. Smith, J. Appl. Phys. 87, 2245 (2000).

${ }^{10}$ L. Vescan, M. Goryll, T. Stoica, P. Gartner, K. Grimm, O. Chretien, E. Mateeva, C. Dieker, and B. Holländer, Appl. Phys. A: Mater. Sci. Process. A71, 423 (2000).

${ }^{11}$ M. Goryll, L. Vescan, and H. Lüth, Thin Solid Films 336, 244 (1998).

${ }^{12}$ M. Goryll, L. Vescan, K. Schmidt, S. Mesters, and H. Lüth, Appl. Phys. Lett. 71, 410 (1997).

${ }^{13}$ A. Souifi, G. Brémond, T. Benyattou, G. Guillot, D. Dutartre, and I. Berbezier, J. Vac. Sci. Technol. B 10, 2002 (1992).

${ }^{14}$ T. Brunhes et al., Appl. Phys. Lett. 77, 1822 (2000).

${ }^{15}$ C. S. Peng, Q. Huang, W. Q. Cheng, J. M. Zhou, Y. H. Zhang, T. T. Sheng, and C. H. Tung, Phys. Rev. B 57, 8805 (1998).

${ }^{16}$ H. Chen, W. Q. Cheng, X. G. Xie, Q. Huang, and J. M. Zhou, J. Cryst. Growth 171, 61 (1997).

${ }^{17}$ J. P. Liu, J. Z. Wang, D. D. Huang, J. P. Li, D. Z. Sun, and M. Y. Kong, J. Cryst. Growth 207, 150 (1999).

${ }^{18}$ P. Sutter and M. G. Lagally, Phys. Rev. Lett. 81, 3471 (1998).

${ }^{19}$ M. Meuris, S. Verhaverbeke, P. W. Mertens, H. F. Schmidt, A. L. P. Rotondaro, and M. M. Heyns, Proc-Electrochem. Soc. PV94-7, 15 (1994).

${ }^{20}$ M. Meuris et al., Proceedings of the 1999 IEEE International Symposium 
on Semiconductor Manufacturing, 1999, p. 157.

${ }^{21}$ J. A. Floro, G. A. Lucadamo, E. Chason, L. B. Freund, M. Sinclair, R. D. Twesten, and R. Q. Hwang, Phys. Rev. Lett. 80, 4717 (1998).

${ }^{22}$ P. Sutter, E. Matteeva, J. S. Sullivan, and M. G. Lagally, Thin Solid Films 336, 262 (1998).

${ }^{23}$ A. Souifi, T. Benyattou, G. Guillot, G. Brémond, D. Dutartre, and P. Warren, J. Appl. Phys. 78, 4039 (1995).

${ }^{24}$ R. Loo et al., Thin Solid Films 336, 227 (1998).

${ }^{25}$ A. Hartmann, C. Dieker, U. Bangert, R. Loo, L. Vescan, and H. Lüth, Appl. Surf. Sci. 104/105, 502 (1996).
${ }^{26}$ A. St. Amour, J. C. Sturm, Y. Lacroix, and M. L. W. Thewalt, Appl. Phys. Lett. 65, 3344 (1994).

${ }^{27}$ I. A. Buyanova, W. M. Chen, A. Henry, W.-X. Ni, G. V. Hansson, and B. Monemar, Appl. Surf. Sci. 102, 293 (1996).

${ }^{28}$ I. A. Buyanova, W. M. Chen, G. Pozina, B. Monemar, W.-X. Ni, and G. V. Hansson, Appl. Phys. Lett. 71, 3676 (1997).

${ }^{29}$ L. Vescan and T. Stoica, Proc. SPIE 3630, 163 (1999).

${ }^{30}$ J. Konle, H. Presting, H. Kibbel, K. Thonke, and R. Sauer, International Conference on Communications, Computers and Devices (ICCCD-2000), 14-16 December 2000, Kharagpur, India (to be published). 